\title{
Value Investment Based on Data Analysis with Comparison of Three Insurance Corporations in the US
}

\author{
Jinnan Sun \\ School of Mathematics, Liaoning University Shenyang City, Liaoning Province, 110036, China
}

\begin{abstract}
Value investment analysis plays a crucial role in people's judgment of whether an enterprise is worthy of continuing investment. Because it helps people reduce the likelihood of making a bad investment, whether it's worth it, and how do you combine the various factors. The purpose of this paper is to analyze the value of the company's investment in the insurance industry. AIG, ALL and MET were selected from a large number of insurance companies. Using $\mathrm{P} / \mathrm{E}$ and $\mathrm{P} / \mathrm{S}$ ratio to compare the prospects of several companies of the same type through specific data, investment analysis. Finally, the best companies to invest in among the three companies are obtained by combining the display situation, and give final investment advice.
\end{abstract}

\section{Introduction}

Value investing is looking for stocks that are priced below their intrinsic value and holding them for a period of time until their price exceeds their intrinsic value. During this process, many factors need to be considered in order to make better decisions, such as market conditions, internal management of the company, financial affairs, personnel changes and so on. In this paper, $\mathrm{P} / \mathrm{E}, \mathrm{P} / \mathrm{S}, \mathrm{PEG}$ and internal management factor are used to determine whether the selected enterprise is worth the investment.

$\mathrm{P} / \mathrm{E}$ ratios are used by investors and analysts to determine the relative value of a company's shares in an apples-to-apples comparison. It can also be used to compare a company against its historical record or to compare aggregate markets against one another or over time. The equation 1 for it is showing below:

\section{$\mathrm{P} / \mathrm{E}$ Ratio=Market value per share/Earnings per share (1)}

As for PEG, it is used to determine a stock's value while taking the company's earnings growth into account and is considered to provide a more complete picture than the $\mathrm{P} / \mathrm{E}$ ratio.

The $\mathrm{P} / \mathrm{S}$ ratio can be calculated either by dividing the company's market capitalization by its total sales over a designated period - usually twelve months, or on a per-share basis by dividing the stock price by sales per share. The $\mathrm{P} / \mathrm{S}$ ratio is also known as a sales multiple or revenue multiple.

$\mathrm{P} / \mathrm{E}$ Ratio=Market value per share/Sales per share (2)
These ratios play an important role in summarizing and evaluating a company's financial position and business performance.

\section{COMPANY BACKGROUND AND FINANCIAL SITUATION}

The paper will discuss the financial condition from several important indicators mostly.

\subsection{AIG}

American International Group (AIG) is a Group of International insurance and financial services companies based in the United States, headquartered in the American International building in New York City. The group's headquarters in the UK are located in Fenchurch Street in London, its headquarters in continental Europe are located in La Defense in Paris, and its headquarters in Asia are located in Hong Kong.

$P / E$ ratio. Table 1 shows stock prices and earnings per share in different fiscal quarters. AIG's stock is trading at $\$ 53.28$, and then earnings per share are calculated based on the updated four-quarter earnings per share selected. Then earnings per share is divided by the stock price to get the current $\mathrm{p} / \mathrm{e}$ ratio, which is 32.10 . If you take the forecast and you put it into the forecast, you get the projected future $\mathrm{p} / \mathrm{e}$ is 11.56 .

AIG's current $\mathrm{P} / \mathrm{E}$ ratio is quite different from its forward $\mathrm{P} / \mathrm{E}$ ratio. The Current $\mathrm{P} / \mathrm{E}$ ratio of $\mathrm{AIG}$ is very high. After data search on Internet, I found the reasons of AIG lose money are the increased spending to repay government loans and the reduction in its cash reserves. 
Table 1. AIG's $\mathrm{P} / \mathrm{E}$ ratio.

\begin{tabular}{|c|c|c|c|c|c|}
\hline \multicolumn{6}{|c|}{ Current $\mathrm{P} / \mathrm{E}$} \\
\hline FQ2 '18 & FQ3 '18 & FQ4 '18 & FQ1 '19 & EPS & $\mathrm{P} / \mathrm{E}$ \\
\hline 1.05 & -0.34 & -0.63 & 1.58 & 1.66 & 32.10 \\
\hline \multicolumn{6}{|c|}{ Forward P/E } \\
\hline FQ2 '19 & FQ3 '19 & FQ4 '19 & FQ1 '20 & EPS & $\mathrm{P} / \mathrm{E}$ \\
\hline 1.13 & 1.06 & 1.14 & 1.28 & 4.61 & 11.56 \\
\hline \multicolumn{6}{|c|}{ P/E-to-growth (PEG) } \\
\hline \multicolumn{2}{|c|}{ Price } & \multicolumn{2}{|c|}{ EPS growth } & \multicolumn{2}{|c|}{ PEG } \\
\hline \multicolumn{2}{|c|}{53.28} & \multicolumn{2}{|c|}{$177.7 \%$} & \multicolumn{2}{|c|}{0.18} \\
\hline
\end{tabular}

$P / S$ ratio. The $\mathrm{P} / \mathrm{S}$ ratio is equal to the stock price divided by the sales per share. According to the sales volume and stock price of each quarter in Table 2 , it can be calculated that the price-to-sales ratio of the three quarters after 2018 plus the first quarter of 2019, i.e.
AIG's P/S ratio as a whole looks stable. Current and future $\mathrm{P} / \mathrm{E}$ ratios are less than one, indicating that the company's shares are undervalued. AIG's stock is worth investing in from a price-to-sales point of view alone.

Table 2. AIG's $\mathrm{P} / \mathrm{S}$ ratio.

\begin{tabular}{|c|c|c|c|c|c|c|c|}
\hline \multicolumn{8}{|c|}{ Current $\mathrm{P} / \mathrm{S}$} \\
\hline FQ2 '18 & FQ3 '18 & FQ4 '18 & FQ1' 19 & Sales & SHO & Sales per share & $\mathrm{P} / \mathrm{S}$ ratio \\
\hline $11,631,000,000$ & $11,486,000,000$ & $12,560,000,000$ & $12,456,000,000$ & $48,133,000,000$ & $869,753,584$ & 55.34 & 0.963 \\
\hline \multicolumn{8}{|c|}{ Forward $\mathrm{P} / \mathrm{S}$} \\
\hline FQ2 '19 & FQ3 '19 & FQ4 '19 & FQ1 '20 & Sales & SHO & Sales per share & $\mathrm{P} / \mathrm{S}$ ratio \\
\hline $12,000,000,000$ & $12,100,000,000$ & $12,100,000,000$ & $12,200,000,000$ & $48,400,000,000$ & $869,753,584$ & 55.65 & 0.957 \\
\hline \multicolumn{8}{|c|}{ P/S-to-growth ratio } \\
\hline \multicolumn{2}{|c|}{ Price } & \multicolumn{2}{|c|}{$\mathrm{P} / \mathrm{S}$ ratio } & \multicolumn{2}{|c|}{ Sales growth } & \multicolumn{2}{|c|}{ PSG ratio } \\
\hline \multicolumn{2}{|c|}{53.28} & \multicolumn{2}{|c|}{0.960} & \multicolumn{2}{|c|}{$1 \%$} & \multicolumn{2}{|c|}{1.73} \\
\hline
\end{tabular}

\subsection{ALL}

Allstate is the second-largest private insurer in the country and has a wide range of public insurers. The company also has an individual insurance business in Canada. The company was founded in 1931 and is headquartered in Illinois. The company attaches great importance to corporate culture. It is an enterprise that loves sports. So far, it has sponsored many sports programs, including Allstate Sugar Bowl, American Olympic association and so on.

Allstate insurance company's insurance products include auto insurance, family insurance, small villa insurance, personal property plan insurance, commercial vehicles, Marine products, entrepreneurs, customers and business package policies, etc., from family insurance, business insurance, personal insurance, auto insurance, natural disaster insurance, etc.

$P / E$ ratio. As can be seen from Table 3, ALL shares are currently trading at $\$ 101.69$ and EPS is calculated based on the latest EPS for the fourth quarter. The current $\mathrm{p} / \mathrm{e}$ is 13.80 and the predicted future $\mathrm{P} / \mathrm{E}$ is 10.88 .

From the numerical point of view, both now and future $\mathrm{p} / \mathrm{e}$ are not high, cut in the state of decline. This phenomenon from the side reflects that the enterprise has a good development prospects, from this point of view, the stock of ALL company is worth investing. 
Table 3. All's PE ratio

\begin{tabular}{|c|c|c|c|c|c|}
\hline \multicolumn{6}{|c|}{ Current $\mathrm{P} / \mathrm{E}$} \\
\hline FQ2 ' 18 & FQ3 '18 & FQ4 '18 & FQ1 '19 & EPS & $\mathrm{P} / \mathrm{E}$ \\
\hline 1.9 & 1.93 & 1.24 & 2.3 & 7.37 & 13.80 \\
\hline \multicolumn{6}{|c|}{ Forward P/E } \\
\hline FQ2 ' 19 & FQ3 '19 & FQ4 '19 & FQ1 '20 & EPS & $\mathrm{P} / \mathrm{E}$ \\
\hline 1.71 & 2.15 & 2.72 & 2.77 & 9.35 & 10.88 \\
\hline \multicolumn{6}{|c|}{ P/E-to-growth (PEG) } \\
\hline \multicolumn{2}{|c|}{ Price } & \multicolumn{2}{|c|}{ EPS growth } & \multicolumn{2}{|c|}{ PEG } \\
\hline \multicolumn{2}{|c|}{101.69} & \multicolumn{2}{|c|}{$26.9 \%$} & \multicolumn{2}{|c|}{0.51} \\
\hline
\end{tabular}

$P / S$ ratio. According to the sales volume and stock price of each quarter in Table 4, we can calculate the $\mathrm{P} / \mathrm{S}$ ratio that appears to be 0.995 , and predict the $\mathrm{P} / \mathrm{S}$ ratio of 0.946 in the coming year. According to the data, compared with the present, the future $\mathrm{P} / \mathrm{S}$ ratio is lower, and both of them are less than one, indicating that the current company's stock value is undervalued. Finally, the value of PSG calculated is 0.19 , which is also in a low value state, so the stock of ALL company is also worth investing.

Table 4. All's PS ratio

\begin{tabular}{|c|c|c|c|c|c|c|c|}
\hline \multicolumn{8}{|c|}{ Current $\mathrm{P} / \mathrm{S}$} \\
\hline FQ2 '18 & FQ3 '18 & FQ4 '18 & FQ1'19 & Sales & SHO & Sales per share & $\mathrm{P} / \mathrm{S}$ ratio \\
\hline $8,541,000,000$ & $8,800,000,000$ & $8,370,000,000$ & $8,327,000,000$ & $34,038,000,000$ & $333,106,827$ & 102.18 & 0.995 \\
\hline \multicolumn{8}{|c|}{ Forward $\mathrm{P} / \mathrm{S}$} \\
\hline FQ2 ' 19 & FQ3 '19 & FQ4 '19 & FQ1 '20 & Sales & $\mathrm{SHO}$ & Sales per share & $\mathrm{P} / \mathrm{S}$ ratio \\
\hline $9,000,000,000$ & $9,200,000,000$ & $8,800,000,000$ & $8,800,000,000$ & $35,800,000,000$ & $333,106,827$ & 107.47 & 0.946 \\
\hline \multicolumn{8}{|c|}{ P/S-to-growth ratio } \\
\hline \multicolumn{2}{|c|}{ Price } & \multicolumn{2}{|c|}{$\mathrm{P} / \mathrm{S}$ ratio } & \multicolumn{2}{|c|}{ Sales growth } & \multicolumn{2}{|c|}{ PSG ratio } \\
\hline \multicolumn{2}{|c|}{101.69} & \multicolumn{2}{|c|}{0.995} & \multicolumn{2}{|c|}{$5 \%$} & \multicolumn{2}{|c|}{0.19} \\
\hline
\end{tabular}

\subsection{MET}

Metlife is a leading provider of insurance and other financial services to millions of individual and corporate customers across the United States, including 88 of the fortune 500's top 100 companies. In addition to the United States, the group also has direct branch insurance institutions in the asia-pacific region, Latin America and Europe.

$P / E$ ratio. As can be seen from Table 5, the stock price of MET is currently $\$ 49.76$, and the current $\mathrm{p} / \mathrm{e}$ ratio of 9.03 can be calculated based on the known data. The predicted future $\mathrm{p} / \mathrm{e}$ is 8.84 . It can be seen from the calculated value that the $\mathrm{P} / \mathrm{E}$ ratio of MET company as a whole is in a low state.

At the same time, the PEG of MET can be calculated as 4.15 based on the data available. Although the $\mathrm{P} / \mathrm{E}$ ratio of the company is low, its PEG value is relatively high compared with the previous two companies. So it is impossible to accurately judge whether the company is worth investing in from a price-to-earnings perspective alone. 
Table 5. MET's PE ratio

\begin{tabular}{|c|c|c|c|c|c|}
\hline \multicolumn{6}{|c|}{ Current P/E } \\
\hline FQ2 ' 18 & FQ3 '18 & FQ4 '18 & FQ1 '19 & EPS & $\mathrm{P} / \mathrm{E}$ \\
\hline 1.30 & 1.38 & 1.35 & 1.48 & 5.51 & 9.03 \\
\hline \multicolumn{6}{|c|}{ Forward P/E } \\
\hline FQ2 '19 & FQ3 '19 & FQ4 '19 & FQ1 '20 & EPS & $\mathrm{P} / \mathrm{E}$ \\
\hline 1.34 & 1.41 & 1.40 & 1.48 & 5.63 & 8.84 \\
\hline \multicolumn{6}{|c|}{ P/E-to-growth (PEG) } \\
\hline \multicolumn{2}{|c|}{ Price } & \multicolumn{2}{|c|}{ EPS growth } & \multicolumn{2}{|c|}{ PEG } \\
\hline \multicolumn{2}{|c|}{49.76} & \multicolumn{2}{|c|}{$2.2 \%$} & \multicolumn{2}{|c|}{4.15} \\
\hline
\end{tabular}

$P / S$ ratio. Similarly, based on the sales volume and stock price of each quarter in figure 6 , the price-to-sales ratio appearing in figure 6 can be calculated as 0.691 , and the price-to-sales ratio of the next year can be predicted as 0.714 . As with the previous two companies, both the current and projected $\mathrm{P} / \mathrm{S}$ ratios are less than one, which is a good performance. However, when calculating the PSG value, as the sales per share is reduced, the calculated PSG is negative and there is no positive reference significance. Therefore, the stock of MET company is not worth investing in.

Table 6. MET's PS ratio

\begin{tabular}{|c|c|c|c|c|c|c|c|}
\hline \multicolumn{8}{|c|}{ Current $\mathrm{P} / \mathrm{S}$} \\
\hline FQ2 ' 18 & FQ3 '18 & FQ4 ' 18 & FQ1' 19 & Sales & $\mathrm{SHO}$ & Sales per share & $\mathrm{P} / \mathrm{S}$ ratio \\
\hline $21,216,000,000$ & $16,400,000,000$ & $15,397,000,000$ & $15,448,000,000$ & $68,461,000,000$ & $950,369,436$ & 72.04 & 0.691 \\
\hline \multicolumn{8}{|c|}{ Forward $\mathrm{P} / \mathrm{S}$} \\
\hline FQ2 '19 & FQ3 '19 & FQ4 '19 & FQ1 '20 & Sales & $\mathrm{SHO}$ & Sales per share & $\mathrm{P} / \mathrm{S}$ ratio \\
\hline $16,500,000,000$ & $16,700,000,000$ & $16,500,000,000$ & $16,500,000,000$ & $66,200,000,000$ & $950,369,436$ & 69.66 & 0.714 \\
\hline \multicolumn{8}{|c|}{$\mathrm{P} / \mathrm{S}$-to-growth ratio } \\
\hline \multicolumn{2}{|c|}{ Price } & \multicolumn{2}{|c|}{$\mathrm{P} / \mathrm{S}$ ratio } & \multicolumn{2}{|c|}{ Sales growth } & \multicolumn{2}{|c|}{ PSG ratio } \\
\hline \multicolumn{2}{|c|}{49.76} & \multicolumn{2}{|c|}{0.030} & \multicolumn{2}{|c|}{$-3 \%$} & & \\
\hline
\end{tabular}

\section{Comparison and Analysis}

\subsection{P/E aspect}

MetLife has the smallest number in both Current P/E ratio and Forward $\mathrm{P} / \mathrm{E}$ ratio, and it means that the company is the most likely to be profitable.

The Current $\mathrm{P} / \mathrm{E}$ ratio of AIG is very high. After data search on Internet, the author found the reasons of AIG lose money are the increased spending to repay government loans and the reduction in its cash reserves.

In Table 7, it is clear that the difference in AIG's P/E ratio is the largest, with ALL and MET ranking second and third respectively. $\mathrm{P} / \mathrm{E}$ ratio can describe the relative valuation of stocks across their industry groups. So when you compare the three companies together, it's clear that AIG has fallen the most. That means AIG is doing best compared with the past, even if its price-to-earnings ratio is not the lowest. At the same time, we can also find that ALL has a good performance, because there is still a large decline in the case of low $\mathrm{P} / \mathrm{E}$ ratio.

In terms of $\mathrm{PEG}$, having $\mathrm{P} / \mathrm{E}$ divided by growth ratio can it be figured out. Since the higher the growth ratio is, the more valuable a stock is, it will be worth investing if PEG is low.

The PEG ratio shows that AIG is the company with the most potential for development. Although the company lost money last year, it can make a profit in the future.

The PEG ratio of MetLife is very high, After data search on Internet, the author found that the company's internal management is a little terrible. Therefore, the company might gets bad in the future. 
Table 7. Comparison among AIG ALL and MET in price, current $\mathrm{P} / \mathrm{E}$, forward $\mathrm{P} / \mathrm{E}$ and $\mathrm{PEG}$ ratio

\begin{tabular}{|c|c|c|c|c|}
\hline & Price & Current P/E & Forward P/E & PEG ratio \\
\hline AIG & 53.28 & 32.10 & 11.56 & 0.18 \\
\hline Allstate & 101.69 & 13.80 & 10.88 & 0.51 \\
\hline MetLife & 49.76 & 9.03 & 8.84 & 4.15 \\
\hline
\end{tabular}

\subsection{P/S aspect}

The $\mathrm{P} / \mathrm{S}$ ratio plays a big role in assessing stocks that are about to make a profit. If a company trades at a lower price-to-earnings ratio than its profitable competitor, investors can buy the stock. The lower a company's PSG value, the better it is for investors to invest.

The $\mathrm{P} / \mathrm{S}$ ratio is equal to the stock divided by the sales per share. The current $\mathrm{p} / \mathrm{e}$ ratio of the three companies is $0.963,0.995$ and 0.691 , and the estimated future $\mathrm{p} / \mathrm{e}$ ratio is $0.957,0.946$ and 0.741 . However, it can be seen from the data that the future $\mathrm{P} / \mathrm{E}$ ratio of met company is higher than the current $\mathrm{P} / \mathrm{E}$ ratio, so its $\mathrm{PSG}$ is negative, which can predict the future development state of the company is not as good as the current one.
So even though the met has the lowest $\mathrm{P} / \mathrm{E}$ of the three, it is not worth it.

MET has the best performance in current $\mathrm{P} / \mathrm{S}$ ratio and forward $\mathrm{P} / \mathrm{S}$ ratio. According to $\mathrm{PSG}$ ratio, Allstate is the best performance company because it has the lowest PSG ratio. AIG, the insurance group that dominated the insurance industry for decades, was ultimately bailed out by a lack of solidity, and investors lost big.

Although the $\mathrm{P} / \mathrm{S}$ ratio of AIG and ALL is less than one, the PSG value of AIG is as high as 1.73 when its stock price is only 53.28, indicating that AIG's investment value is not very high. From this point of view, the stock of ALL company has great investment value at present.

Table 8. Comparison among AIG ALL and MET in price, current $\mathrm{P} / \mathrm{s}$, forward $\mathrm{P} / \mathrm{s}$ and $\mathrm{PSG}$ ratio

\begin{tabular}{|c|c|c|c|c|}
\hline & Price & Current P/S & Forward P/S & PSG ratio \\
\hline AIG & 53.28 & 0.963 & 0.957 & 1.73 \\
\hline Allstate & 101.69 & 0.995 & 0.946 & 0.19 \\
\hline MetLife & 49.76 & 0.691 & 0.714 & \\
\hline
\end{tabular}

\section{CONCLUSION}

The most valuable stock among the three companies is ALL. Although the P/E ratio is not the lowest among the three companies, ALL still has great investment value from the perspective of the predicted $\mathrm{P} / \mathrm{E}$ ratio, $\mathrm{P} / \mathrm{S}$ ratio less than one and the low PEG and PSG.

AIG is mainly due to the company's internal management personnel changes, as well as the company's own debt problems have a certain impact on the calculated indicators. But in terms of $\mathrm{P} / \mathrm{S}$ ratios alone, AIG's shares are still undervalued. If the company can properly handle its own problems in the later stage, ALG still has some room for appreciation.

Although MET's PS ratio was the lowest of the three, its PEG was too high and its PSG was negative. The data suggest that investing in the company is risky and therefore not recommended.

Financial tools could be used to analyze investment. After the comparison, company Allstate is worth to invest on. Allstate has the lowest PSG ratio, and it has good performance in $\mathrm{P} / \mathrm{E}$ ratio, $\mathrm{P} / \mathrm{S}$ ratio and $\mathrm{PEG}$ ratio.

\section{Acknowledgment}

First and foremost, I would like to show my deepest gratitude to my teachers and professors in my university, who have provided me with valuable guidance in every stage of the writing of this thesis. Further, I would like to thank all my friends and roommates for their encouragement and support. Without all their enlightening instruction and impressive kindness, I could not have completed my thesis.

\section{REFERENCES}

1. Sec.gov. (2019). SEC.gov | Company Search Page. [online] Available at: https://www.sec.gov/edgar/searchedgar/companysea rch.html [Accessed 9 Mar. 2019]. 
2. Sec.gov.(2019). Document. [online] Available at: https://www.sec.gov/Archives/edgar/data/1099219/0 00109921919000028/met-2019331x10q.htm[Access ed 9 Mar. 2019].

3. Estimize.com.(2019). Estimize. [online] Available at: https://www.estimize.com/ [Accessed 9 Mar. 2019].

4. Estimize.com. (2019). Estimize. [online] Available at: https://www.estimize.com/met/fq2-2019 ?metric_na me=eps\&chart=historical/[Accessed 9 Mar. 2019].

5. Investopedia. (2019). What the Price-to-Earnings Ratio Tells Us. [online] Available at: https://www.investopedia.com/terms/p/price-earning sratio.asp [Accessed 9 Mar. 2019].

6. Investopedia. (2019). Why the Price/Earnings-to-Growth Ratio Matters. [online] Available at: https://www.investopedia.com/terms/p/pegratio.asp [Accessed 9 Mar. 2019].

7. Investopedia. (2019). What the Price-to-Earnings Ratio Tells Us. [online] Available at: https://www.investopedia.com/terms/p/price-to-sales ratio.asp [Accessed 9 Mar. 2019]. 